Military Technical College Kobry El-Kobbah, Cairo, Egypt.

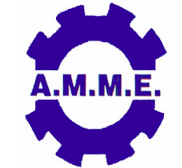

$15^{\text {th }}$ International Conference on Applied Mechanics and Mechanical Engineering.

\title{
NUMERICAL INVESTIGATION OF A HIGH-SPEED PROJECTILE PENETRATION INTO BI-LAYERED LIGHTWEIGHT TARGETS
}

\author{
M. A. Shaker*, H.A. Abou-Elela*, A.M. Riad* and A. I. Fayed*
}

\begin{abstract}
In this paper, Autodyn-3D hydrocode is used to simulate the penetration process of small caliber steel projectiles into bi-layered targets with finite thicknesses consisting of silicon carbide ceramic facing tile backed by kevlar/epoxy composite plate. The numerical results of the hydrocode program are used to assess the predictions of the proposed analytical model [7]. So, the input data of the projectile and target materials to the hydrocode are coincide with that input to the analytical model [7]. These data include geometries of projectile and target as well as mechanical and physical properties of their materials such as density, modulus of elasticity, yield strength and Poisson's ratio. The main procedures used to simulate the penetration process are introduced.
\end{abstract}

The obtained numerical results are compared with the predictions of the analytical model [7] due to the impact of a Fragment Simulated Projectile (FSP) having the same penetration capability as that of $7.62 \mathrm{~mm}$ NATO projectile [8] into ceramic/composite targets with different velocities; good agreement is generally obtained. In addition, Samples of the time histories results predicted by the hydrocode are presented with analyses and discussions. Finally, It can conclud that the Autodyn-3D hydrocode is considered as a quick tool for designing and optimizing the bi-element lightweight armour capable of defeating a projectile of certain threat.

\section{KEY WORDS}

Bi-element targets, ceramics, composites, penetration, ceramic/composite targets, Autodyn, numerical simulation.

* Egyptian Armed Forces. 


\section{INTRODUCTION}

Modeling impact and penetration problems have been the subject of much interest especially for their applications at defense and space technology. The complexity of the penetration process analysis lies in the fact that different and high number of intervening parameters govern the penetration process like relative velocity, shape of colliding objects, relative stiffness and masses, location of contact, dimensions and boundary conditions, material characteristics and distinct failure modes that may occur. Hence, the design of ceramic/composite armour systems based on the understanding of real impact event, is really challenging subject and deserves a sophisticated research work.

Although experimental approach offers most accurate results, it is expensive and sometimes does not provide detail information of the impact event. Ballistic impact simulation is one of the main approaches that used to understand impact and penetration phenomena, and helps in tunning the analytical results used for designing and optimizing bi-element armours. Computational techniques become feasible and cost effective to reduce the physical experimentations and also optimize the parameters involved. Moreover, numerical simulation efficiency reveals when studying impact phenomena in a wide range of impact velocities and high obliquity, where experimental work will be very costly.

Benloulo and Galvez [1] developed one-dimensional analytical model of ballistic penetration of ceramic/composite armours. Their analytical model was checked by comparing its results with those of ballistic tests and numerical simulation; good agreement was obtained. The model was capable of calculating the residual velocity, residual mass, projectile velocity and the deflection or the strain histories of the backup material besides comparing the projectile velocity history calculated analytically with the corresponding ones obtained numerically as shown in Fig.1. The development of their analytical model for composite penetration was based on previous studies of the impact in yarns, fabrics and finally composites [2].

Fawaz et. al. [3] presented a three dimensional finite element model that investigated the performance of ceramic/composite armours when subjected to normal and oblique impacts by 7.62 AP projectiles. The simulation, of penetration process as well as the evaluation of energy and stresses distributions within the impact zones, was done using Ls-dyna 3D finite element code and the results were compared with the experimental data reported by Mayseless [4]. The simulation results showed that the time histories of global kinetic, internal and total energy are similar for normal and oblique impact. Moreover, the interlaminar stresses at the ceramic/composite interface and the forces at the projectile-ceramic interface for oblique impact were found to be smaller than those for normal impact. Finally, they observed that the projectile erosion in oblique impact was slightly greater than that in normal impact.

Peskes and Barbero [5] used Autodyn-2D hydrodynamic code for the parametrical study of the add-on armour systems which consisted of a ceramic top layer supported by metal or composite backing plate and understanding the effect of individual parameters on the ballistic performance of these types of systems. They discussed some aspects with respect to ceramic and various backing layer 
properties. They established a design tool based on a large scale testing program, including both ballistic tests and material characterizations. Finally, they observed the following during their experimental program: (i) the tested ceramic types showed significant differences in ballistic behavior, (ii) the application of different composite materials as backing plate did not result in significant differences in ballistic behavior, and (iii) the change in backing layer thickness was less effective than the change of ceramic tile thickness.

Shokrieh and Javadpour [6] used Ansys/Lsdyna software to predict the ballistic limit of armour consisting of two layers; boron carbide ceramic tile backed by Kevlar 49 fiber composite plate. They also verified Hetherington equation (optimum thickness of layers) for constant thickness of the armour. Their numerical results have confirmed the validity of Benloulo and Galvez analytical model [1]. Moreover, the projectile velocity prediction, especially at high velocity, showed good agreement with numerical simulations. Beside, normal and oblique impact of projectiles into armours have been simulated and compared. The results showed that the ballistic limit of armour increases under oblique impact conditions.

In this paper, Autodyn-3D is used to simulate the penetration process of steel cylinderical projectiles into bi-layered targets consisting of Silicon carbide ceramic facing tile backed by Kevlar/epoxy composite backing plate. The input data used in this code for projectile and target materials, respectively, as well as the procedures used to simulate the penetration process are presented. The obtained numerical results are compared with the predictions of the analytical model [7] due to the impact of a projectile having the same penetration capability as that of a $7.62 \mathrm{~mm}$ NATO projectile [8] into ceramic/composite targets with different velocities. In addition, samples of the obtained numerical results will be presented with relevant analyses and discussions.

\section{NUMERICAL SIMULATION}

Autodyn-3D hydrocode is interactive non-linear dynamic analysis software. This program is used for solving a wide variety of non-linear events in solid, fluid and gas dynamics and specially designed to analyze the behavior of materials under transient dynamic loading. This software is based on explicit finite difference techniques that use a set of material models, initial conditions and boundary conditions beside a set of partial differential equations for conservation of mass, momentum and energy which solved numerically together with the constitutive equations using an explicit time integration scheme to define the complete solution of the problem. Autodyn-3D hydrocode includes seven different solver techniques called processors. These are: Lagrange, Euler, Euler-FCT, Euler-Godunov (Beta), ALE (Arbitrary Lagrange Euler), Shell and SPH (smoothed Particle Hydrodynamics) processors. These processors require the complex problem to be broken up into a finite number of smaller, simpler problems. This process is called discretisation in which all the equations need to be discretised in time and space [9].

Autodyn-3D is used herein to simulate the impact process of a steel cylinderical projectile with initial mass of $7 \mathrm{~g}$, initial length of $31.8 \mathrm{~mm}$ and initial diameter of 6 
$\mathrm{mm}$, into bi-layered targets at different velocities, Cf. Fig.2. Each target consists of a square ( $\mathrm{SiC}$ ) ceramic facing tile backed with a square (Kevlar/epoxy) composite plate.

\section{Model Representation Procedures in Autodyn-3D Hydrocode}

To model any system, it must be drawn considering its datum point or zero origin. Each material or component is discredited into forming cells or meshes. Each mesh interacts with another one by defined strength model for each material that has an equation of state (EOS). The line of interaction between materials is defined as well as time step is determined in order to satisfy the stability condition for the problem. Finally, a great matrix of unknowns is solved for non-linear system indicating each effect of stresses on the whole materials. The main representation procedures of the current problem in Autodyn-3D are [9]:

- Selecting problem symmetry and the used measuring units.

- Loading the material data of projectile and target with their corresponding (EOS) and models of strength, failure, and erosion, respectively.

- Choose "Lagrange" processor for all elements (projectile, ceramic tile and composite plate), then define geometry and zoning of each part.

- Filling each part with its corresponding material and joining the bi-element target (ceramic/composite).

- Setting initial condition (impact velocity) and the boundaries.

- Setting interactions between the parts and check interaction gap.

- Setting the specific data to run the program (time step, cycle limit ....etc).

- Define solution control, and the output.

\section{Material Description}

The material used for filling the meshes of projectile grids was steel. This projectile has a flat-ended cylinderical shape; all of its data are presented in Ref. [8]. The penetration capability of the simulated steel projectile into $\mathrm{RHA}$ was equivalent to that of a $7.62 \times 51 \mathrm{~mm}$ NATO (AP) projectile [8]. The input data to the code for the projectile material used in the present work are listed in Table 1.

The materials used for filling the meshes of each bi-layered target were Silicon Carbide ( $\mathrm{SiC}$ ) as a ceramic facing tile, and Kevlar/epoxy as a composite backing plate. Both ceramic tile and composite plate are presented with the same dimensions in length and width $(150 \mathrm{~mm} \times 150 \mathrm{~mm})$ but different in thicknesses. The input data fed to the code are listed in Table 2 and Table 3 for ceramic tile and composite plate materials, respectively. The main dimensions of the projectile and bi-layered target are converted into subgrids with vertical and horizontal lines (grid lines), Cf. Figs. 3 and 4.

\section{Material Models}

In general, materials have a complex response to dynamic loading. So, to achieve a realistic description of materials behavior, suitable material models such as equation of state, strength model and failure model should be chosen according to the nature of materials involved in the present work. 


\section{Equation of state}

An equation of state is used to describe the hydrodynamic response of the material, i.e. the stress due to changes in volume (volumetric change). For the present analysis, Lagrange processor is used and a "linear" equation of state is used for both projectile and ceramic tile materials, while "orthotropic" equation of state is used for composite plate material. This linear equation of state is expressed by [9]:

$$
\mathrm{P}(\rho)=\mathrm{K} \mu
$$

where

$$
\mu=\left(\left(\rho / \rho_{0}\right)-1\right)
$$

$\mathrm{P}$ is the pressure, $\mathrm{K}$ is the bulk modulus of the respective material, $\mu$ is the compression ratio, $\rho$ is the density of compressed material, and $\rho_{0}$ is its initial density.

The orthotropic equation of state is represented by:

$$
\sigma_{\mathrm{ij}}=S_{\mathrm{ij}} \cdot \varepsilon_{\mathrm{ij}}
$$

where " $S_{i j}$ " is based on elastic constants $E_{11}, E_{22}, E_{33}, v_{12}, v_{31}, v_{23}$ and $G_{12}$ where "E $E_{i i}$ " is Young's moduli in principal directions, " $v_{i j}$ " is Possion's ratios, " $G_{12}$ " is the shear modulus, and " $\varepsilon_{i j}$ " is the principal strain [9].

\section{Strength model}

Material strength equation is used to describe the non-linear elastic-plastic response of the material under extreme shock loadings when the applied stress exceeds its yield stress and the material deforms plastically, i.e. stress due to change in shape (deviatoric change) [9]. For the present analysis, "Von-Mises" yield model is used as a strength model to describe the behavior of the projectile material when simulating its penetration into ceramic/composite targets, "Johnson-Holmquist" ( $\mathrm{JH}-2)$ brittle damage model is used for the ceramic tile material, whereas "Elastic" model is used for the composite plate material.

The "Von-Mises" equation is represented by [9]:

$$
.\left(\sigma_{1}-\sigma_{2}\right)^{2}+\left(\sigma_{2}-\sigma_{3}\right)^{2}+\left(\sigma_{3}-\sigma_{1}\right)^{2}=2 Y^{2}
$$

where $\sigma_{1}, \sigma_{2}$ and $\sigma_{3}$ are the principal stresses, and "Y" is the yield strength.

The "Johnson-Holmquist", (JH-2) Brittle Damage Model, equation is used to represent the brittle materials subjected to large pressures, shear strain and high strain rates. The strength and pressure are normalized by the strength and pressure components of the Hugoniot Elastic Limit (HEL), which allows for many of the constants to be dimensionless. This can be very helpful when comparing different materials. The equivalent stress for a ceramic-type material is [10]: 


$$
\sigma^{*}=\sigma_{i}^{*}-D\left(\sigma_{i}^{*}-\sigma_{f}^{*}\right)
$$

The normalized intact strength is given by [10]:

$$
\sigma_{i}^{*}=A\left(P^{*}+T^{*}\right)^{N}\left(1+C^{*} \ln \varepsilon^{\bullet *}\right)
$$

The normalized fracture strength is given by [10]:

$$
\sigma_{\mathrm{f}}^{*}=\mathrm{B}\left(\mathrm{P}^{*}\right)^{\mathrm{M}}\left(1+\mathrm{C}^{*} \ln \varepsilon^{\bullet *}\right)
$$

where

$$
\sigma^{*}=\sigma / \sigma_{\mathrm{HEL}}
$$

$$
\mathrm{P}^{*}=\mathrm{P} / \mathrm{P}_{\mathrm{HEL}} \quad, \quad \mathrm{T}^{*}=\mathrm{T} / \mathrm{P}_{\mathrm{HEL}},
$$

and

$$
\varepsilon^{\bullet *}=\varepsilon^{\bullet} / \varepsilon_{\mathrm{o}}^{\bullet},
$$

$\sigma_{\mathrm{HEL}}$ is the stress at the (HEL), A, B, C, M, N are dimensionless material parameters, $P$ is the actual pressure and $P_{H E L}$ is the pressure at the HEL, $T$ is the maximum tensile hydrostatic pressure, $\varepsilon^{\bullet}$ is the actual equivalent strain rate and $\varepsilon_{0}^{\bullet}$ is the reference strain rate. The damage parameter $D$ is defined as:

$$
\mathrm{D}=\frac{\sum \Delta \varepsilon^{\mathrm{P}}}{\varepsilon_{\mathrm{f}}^{\mathrm{p}}},
$$

where $\Delta \varepsilon^{\mathrm{p}}$ is the incremental plastic strain per computational cycle, $\varepsilon_{\mathrm{f}}^{\mathrm{p}}$ is the plastic strain to fracture, which is calculated by:

$$
\varepsilon_{\mathrm{f}}^{\mathrm{p}}=\mathrm{D}_{1}\left(\mathrm{P}^{*}+\mathrm{T}^{*}\right)^{\mathrm{D}_{2}}
$$

where, $D_{1}$ and $D_{2}$ are additional damage material constants. Likewise, for each element, fracture occurs when $D=1$ [11]. The actual determination of ceramic parameters is complicated since it can not be determined directly and required different types of testing. Some of these constants, such as B and $M$ which represent fractured strength constant and fractured strength exponent, respectively, may be determined by matching the numerical simulation results with the corresponding experimental measurements [12].

Elastic strength model or orthotropic strength model can be used to describe the behavior of non-isotropic materials such as composite materials. i.e. any strength model with constant or strain dependent yield stress can be used [9]. The linear elastic model implemented in Autodyn uses an incremental stress-strain relationship to calculate the stress at cycle " $n$ " as follows [9]:

$$
[\sigma]^{\mathrm{n}+1}=[\sigma]^{\mathrm{n}}+[\mathrm{S}][\dot{\varepsilon}] \Delta \mathrm{t}
$$


where "[S]" is the stiffness matrix, "[c]" is the strain rate vector, and " $\Delta \mathrm{t}$ " is the time step.

\section{Failure model}

Materials usually fail under extreme loading conditions, resulting in crushed or cracked material. So, failure models are used to simulate the various ways at which materials fail. For the present analysis, no failure model selected for the projectile material, while "Johnson-Holmquist" strength model and "Johnson-Holmquist" failure model must be used together for ceramic tile material and "Material Stress/Strain" is used for the composite plate material.

\section{Erosion Algorithm}

This algorithm allows automatic deletion of cells during calculation when their strain value reaches the erosion strain value. Incremental Geometric strain has been selected for all parts (projectile, ceramic tile, and composite plate). These values are the result of many trials.

\section{Selecting the Solver}

A Lagrangian solver has been selected for all parts, which normally used for modelling of solid continua in which the nodes move with the material. Lagrangian coordinate system will deform with the material and therefore accurately define material interfaces. For the interaction between the projectile and target, Lagrange/Lagrange is used with external gap size which is calculated and checked automatically.

\section{Time Step}

Since the numerical algorithm used in AUTODYN is an explicit scheme, there is an optimum time step of integration which must be determined to obtain a reasonable solution. The local time step ensuring the stability is calculated for each mesh point. The minimum value of all these local values is multiplied by a factor (a default value of $2 / 3$ is built into the code) is chosen as the time step for the next update. In Lagrangian mesh, the time step must satisfy Courant condition [9] so, the time step is represented by:

$$
\Delta \mathrm{t}<\frac{\mathrm{d}}{\mathrm{c}}
$$

where " $d$ " is the typical length of the cell (defined as the area of the cell divided by its longer diagonal) and "c" is the local sound speed. By this, the disturbance will not be able to across more than a cell width during a cycle (single time step). The minimum value of " $\Delta \mathrm{t}$ " must be found for all cells and this value will be used for these cells for the next time step of integration.

\section{Program Running}

After entering all required data and selecting the suitable material models, erosion 
Table 1. Input data to the code for the used projectile materials.

\begin{tabular}{|l|c|l|c|}
\hline \multicolumn{1}{|c|}{ Parameter } & Value & \multicolumn{1}{c|}{ Parameter } & Value \\
\hline Material & steel & Projectile diameter $(\mathrm{mm})$ & 6.0 \\
\hline Equation of state & Linear & Modulus of elasticity $(\mathrm{KPa})$ & $202 \mathrm{E} 6$ \\
\hline Strength model & Von-Mises & Yield stress $(\mathrm{KPa})$ & $7.7199 \mathrm{E} 5$ \\
\hline Failure model & None & Shear modulus $(\mathrm{KPa})$ & $7.769 \mathrm{E} 7$ \\
\hline Reference density $\left(\mathrm{g} / \mathrm{cm}^{3}\right)$ & 7.850 & Bulk modulus $(\mathrm{KPa})$ & $1.68 \mathrm{E} 8$ \\
\hline Reference temperature $\left({ }^{0} \mathrm{~K}\right)$ & 300 & Melting temperature $\left({ }^{\circ} \mathrm{K}\right)$ & 1800 \\
\hline Projectile mass $(\mathrm{g})$ & 7.0 & Erosion & (incremental) \\
\hline Projectile length $(\mathrm{mm})$ & 31.8 & Erosion strain & 1.0 \\
\hline
\end{tabular}

Table 2. Input data to the code for the used ceramic material [11].

\begin{tabular}{|l|c|l|c|}
\hline \multicolumn{1}{|c|}{ Parameter } & Value & \multicolumn{1}{c|}{ Parameter } & Value \\
\hline Material & $\mathrm{SiC}$ & Intact strength constant 'A' & 0.96 \\
\hline Equation of state & Linear & Intact strength exponent 'N' & 0.65 \\
\hline Strength model & $\mathrm{JH}-2$ & Strain rate constant 'C' & 0.0 \\
\hline Failure model & $\mathrm{JH}-2$ & Fractured strength constant 'B' & 0.35 \\
\hline Reference density $\left(\mathrm{g} / \mathrm{cm}^{3}\right)$ & 3.310 & Fractured strength exponent 'M' & 1.0 \\
\hline Reference temperature $\left({ }^{0} \mathrm{~K}\right)$ & 293 & Max. fractured strength ratio & 1.0 \\
\hline Ceramic tile thickness $(\mathrm{mm})$ & Different & Damage constant D1 & 0.48 \\
\hline Ceramic tile length $(\mathrm{mm})$ & 150 & Damage constant D2 & 0.48 \\
\hline Ceramic tile width $(\mathrm{mm})$ & 150 & Bulking constant ' $\beta$ ' & 1.0 \\
\hline Modulus of elasticity $(\mathrm{KPa})$ & $404 \mathrm{E} 6$ & Damage type & Gradual JH2 \\
\hline Hugoniot elastic limit $(\mathrm{KPa})$ & $7.7 \mathrm{E} 6$ & Tensile failure & Hydro $\left(\mathrm{P}_{\min }\right.$. $)$ \\
\hline Shear modulus $(\mathrm{KPa})$ & $1.74 \mathrm{E} 8$ & Erosion & (incremental) \\
\hline Bulk modulus $(\mathrm{KPa})$ & $1.98 \mathrm{E} 8$ & Erosion strain & 1.65 \\
\hline
\end{tabular}

strain and time step, the program was run to predict the residual velocity, depth of penetration at each impact velocity, pressure contours, and time histories of projectile velocity, displacement ...etc.

\section{RESULTS AND DISCUSSIONS}

In the following, samples of the post perforation results, velocity-time histories of the projectile rigid mass and projectile penetration depth-time histories obtained by Autodyn-3D hydrocode and the proposed analytical model [7], respectively, due to the penetration of different thicknesses of bi-element targets by $7.62 \mathrm{~mm}$ FSPs are presented.

\section{Analytical and Numerical Post-Perforation Results}

In the following, the post-perforation velocities obtained by Autodyn-3D hydrocode are compared with the corresponding velocities predicted by analytical model of Ref. [7]. The input data needed to run the hydrocode for projectile, ceramic tile and composite plates are listed in Tables 1, 2, and 3. 
Table 3. Input data to the code for the used composite material [13].

\begin{tabular}{|l|c|l|c|}
\hline \multicolumn{1}{|c|}{ Parameter } & Value & \multicolumn{1}{c|}{ Parameter } & Value \\
\hline Material & Kevlar/Epoxy & Shear Modulus 31 (kPa) & $2.235 \mathrm{E} 5$ \\
\hline Equation of state & Orthotropic & Volumetric response & Polynomial \\
\hline Strength model & Elastic & Bulk modulus 'A1' & $5.864244 \mathrm{E} 6$ \\
\hline Failure model & stress/strain & Parameter 'A2' (kPa) & $5.0 \mathrm{E} 7$ \\
\hline Reference density $\left(\mathrm{g} / \mathrm{cm}^{3}\right)$ & 1.44 & Parameter 'T1' $(\mathrm{kPa})$ & $5.864244 \mathrm{E} 6$ \\
\hline Composite thickness $(\mathrm{mm})$ & Different & Tensile failure stress 11 $(\mathrm{kPa})$ & $4.5 \mathrm{E} 4$ \\
\hline Composite length $(\mathrm{mm})$ & 150 & Tensile failure stress 22 $(\mathrm{kPa})$ & $2.45 \mathrm{E} 5$ \\
\hline Composite width $(\mathrm{mm})$ & 150 & Tensile failure stress 33 $(\mathrm{kPa})$ & $2.45 \mathrm{E} 5$ \\
\hline Modulus of elasticity $(\mathrm{kPa})$ & $99 \mathrm{E} 6$ & Max. shear stress 12 $(\mathrm{kPa})$ & $1.4 \mathrm{E} 4$ \\
\hline Tensile failure strain $(\%)$ & 4.4 & Max. shear stress 23 $(\mathrm{kPa})$ & $2.0 \mathrm{E} 4$ \\
\hline Shear modulus $(\mathrm{kPa})$ & $2.235 \mathrm{E} 5$ & Max. shear stress 31 $(\mathrm{kPa})$ & $1.4 \mathrm{E} 4$ \\
\hline Bulk modulus $(\mathrm{kPa})$ & $5.864244 \mathrm{E} 6$ & Tensile failure strain 11 & 0.044 \\
\hline Young's Modulus 11 $(\mathrm{kPa})$ & $1.948 \mathrm{E} 6$ & Tensile failure strain 22 & 0.06 \\
\hline Young's Modulus 22 $(\mathrm{kPa})$ & $1.7989 \mathrm{E} 7$ & Tensile failure strain 33 & 0.06 \\
\hline Young's Modulus 33 $(\mathrm{kPa})$ & $1.7989 \mathrm{E7}$ & Post failure option & Orthotropic \\
\hline Poisson's ratio 12 & 0.0756 & Max. residual shear stress $(\mathrm{kPa})$ & $1.4 \mathrm{E} 4$ \\
\hline Poisson's ratio 23 & 0.0756 & Residual shear stiffness fraction & 0.2 \\
\hline Poisson's ratio 31 & 0.698 & Erosion & incremental) \\
\hline Shear Modulus 12 $(\mathrm{kPa})$ & $2.235 \mathrm{E} 5$ & Erosion strain & 1.35 \\
\hline Shear Modulus 23 $(\mathrm{kPa})$ & $1.85701 \mathrm{E} 6$ & & \\
\hline
\end{tabular}

Table 4 lists the residual velocities obtained analytically and numerically due to the impact of the considered projectile into different bi-element targets, each of them consists of $\mathrm{SiC}$ ceramic tile backed with Kevlar-129 composite plate, with $\mathrm{V}_{\mathrm{i}}=880$ $[\mathrm{m} / \mathrm{s}]$. Some of the obtained results are also plotted in Fig. 5. For each considered bielement target, the residual velocities obtained by the proposed analytical model [7] and that obtained by Autodyn-3D hydrocode are in good agreement. The maximum absolute relative difference between the analytical and numerical residual velocities is found to be $27.5 \%$ for a bi-element target consisting of $20 \mathrm{~mm}$-thick of SiC ceramic tile backed by $3 \mathrm{~mm}$-thick of Kevlar-129 composite. This result is considered to be questionable because the consequence maximum difference is found to be $13.7 \%$.

Table 5 lists the residual velocities obtained analytically and numerically due to the impact of the considered projectile into different bi-element targets with different impact velocities. The obtained results are also plotted in Fig. 6. For each considered bi-element target, the comparison between the analytical residual velocity and the corresponding numerical one at each impact velocity gives a good agreement. The maximum absolute relative difference between the predicted and numerical residual velocity is found to be $16.6 \%$ when the projectile impacts into a bi-element target consisting of $20 \mathrm{~mm}$-thick of SiC ceramic tile backed by $20 \mathrm{~mm}$ thick of Kevlar129 composite at $\mathrm{V}_{\mathrm{i}}=1100$ [m/s].

The numerical results of Autodyn-3D assess the predictions of the proposed analytical model [7]. In addition, the Autodyn-3D hydrocode could be used as a quick tool for designing a bi-element target capable of defeating a $7.62 \mathrm{~mm}(\mathrm{AP})$ projectile. 
Table 4. Comparison between analytical and numerical residual velocities due to the impact of the considered projectile into different bi-element targets with $V_{i}=880[\mathrm{~m} / \mathrm{s}]$.

\begin{tabular}{|c|c|c|c|c|c|}
\hline \multirow[t]{2}{*}{$\begin{array}{l}\text { Impact } \\
\text { velocity, } \\
V_{i}[\mathrm{~m} / \mathrm{s}]\end{array}$} & \multirow[t]{2}{*}{$\begin{array}{c}\text { Ceramic } \\
\text { thickness, } \\
\mathrm{H}_{\mathrm{co}}[\mathrm{mm}]\end{array}$} & \multirow{2}{*}{$\begin{array}{c}\text { Composite } \\
\text { thickness, } \\
\mathrm{H}_{\mathrm{b}}[\mathrm{mm}]\end{array}$} & $\begin{array}{l}\text { Residual } \\
\text { velocity, } \\
\mathrm{V}_{\mathrm{R}}[\mathrm{m} / \mathrm{s}] \\
\end{array}$ & $\begin{array}{l}\text { Residual } \\
\text { velocity, } \\
\mathrm{V}_{\mathrm{R}}[\mathrm{m} / \mathrm{s}] \\
\end{array}$ & \multirow{2}{*}{$\begin{array}{l}\text { Abs. relative } \\
\text { difference } \\
\Delta \mathrm{V} / \mathrm{V}_{\mathrm{i}}[\%]\end{array}$} \\
\hline & & & Analytical & Numerical & \\
\hline \multirow{5}{*}{880} & \multirow{5}{*}{5} & 3 & 781.01 & 776.16 & 0.6 \\
\hline & & 7 & 722.87 & 728.15 & 0.7 \\
\hline & & 10 & 679.85 & 695.73 & 2.3 \\
\hline & & 15 & 614.99 & 646.12 & 4.8 \\
\hline & & 20 & 554.82 & 612.97 & 9.5 \\
\hline \multirow{5}{*}{880} & \multirow{5}{*}{10} & 3 & 694.45 & 664.19 & 4.6 \\
\hline & & 7 & 603.76 & 597.41 & 1.0 \\
\hline & & 10 & 543.47 & 546.14 & 0.5 \\
\hline & & 15 & 463.46 & 445.73 & 3.9 \\
\hline & & 20 & 386.48 & 376.5 & 2.6 \\
\hline \multirow{5}{*}{880} & \multirow{5}{*}{15} & 3 & 583.11 & 576.19 & 1.2 \\
\hline & & 7 & 491.11 & 519.87 & 13.7 \\
\hline & & 10 & 428.08 & 486.74 & 12.0 \\
\hline & & 15 & 331.03 & 309.89 & 6.8 \\
\hline & & 20 & 247.18 & 218.25 & 13.2 \\
\hline \multirow{5}{*}{880} & \multirow{5}{*}{20} & 3 & 420.42 & 329.53 & 27.5 \\
\hline & & 7 & 326.30 & 306.15 & 6.6 \\
\hline & & 10 & 243.18 & 217.89 & 11.6 \\
\hline & & 15 & 67.20 & 64.89 & 3.5 \\
\hline & & 20 & 0.00 & 0.00 & 0.0 \\
\hline
\end{tabular}

\section{Numerical and Analytical Time-Histories Results}

In the following figures, the velocity-time histories of the projectile rigid mass and projectile penetration depth-time histories obtained by Autodyn-3D hydrocode are plotted with the corresponding analytical ones of Ref. [7].

Figure 7 plots the velocity-time histories of projectile rigid mass during the penetration process of a bi-element target, consisting of $20 \mathrm{~mm}$-thick of SiC ceramic tile backed by $20 \mathrm{~mm}$-thick of Kevlar129 composite plate, by a $7.62 \mathrm{FSP}$ at $\mathrm{V}_{\mathrm{i}}=900$ $[\mathrm{m} / \mathrm{s}]$. Both the analytical model and Autodyn-3D hydrocode predict that the projectile traps by the considered target. It is also predicted that the considered projectile can perforate the target when its impact velocity is slightly greater than 900 $\mathrm{m} / \mathrm{s}$. Therefore, the impact velocity of $900[\mathrm{~m} / \mathrm{s}]$ can be considered as the limit velocity of this bi-element target. However, a slight difference exists between the total time of penetration process obtained numerically and analytically; good agreement is generally obtained between the analytical and numerical velocity-time histories of the projectile rigid mass.

Figure 8 also plots the velocity-time histories of projectile rigid mass during the penetration process of a bi-element target, consisting of $15 \mathrm{~mm}$-thick of SiC ceramic tile backed by $15 \mathrm{~mm}$-thick of Kevlar129 composite plate, by a FSP at $V_{i}=1300$ $[\mathrm{m} / \mathrm{s}]$. A complete penetration of the target has been predicted by the proposed 
Table 5. Comparison between analytical and numerical residual velocities due to the impact of the considered projectile into different bi-element targets with different impact velocities.

\begin{tabular}{|c|c|c|c|c|c|}
\hline \multirow{2}{*}{$\begin{array}{l}\text { Impact } \\
\text { velocity, } \\
V_{i}[\mathrm{~m} / \mathrm{s}]\end{array}$} & \multirow[t]{2}{*}{$\begin{array}{c}\text { Ceramic } \\
\text { thickness, } \\
\mathrm{H}_{\mathrm{co}}[\mathrm{mm}]\end{array}$} & \multirow[t]{2}{*}{$\begin{array}{c}\text { Composite } \\
\text { thickness, } \\
\mathrm{H}_{\mathrm{b}}[\mathrm{mm}]\end{array}$} & $\begin{array}{l}\text { Residual } \\
\text { velocity, } \\
V_{R}[\mathrm{~m} / \mathrm{s}]\end{array}$ & $\begin{array}{l}\text { Residual } \\
\text { velocity, } \\
V_{R}[\mathrm{~m} / \mathrm{s}]\end{array}$ & \multirow{2}{*}{$\begin{array}{l}\text { Abs. relative } \\
\text { difference } \\
\Delta \mathrm{V} / \mathrm{V}_{\mathrm{i}}[\%]\end{array}$} \\
\hline & & & Analytical & Numerical & \\
\hline 900 & \multirow{5}{*}{5} & \multirow{5}{*}{5} & 771.08 & 781.18 & 1.3 \\
\hline 1000 & & & 871.14 & 882.17 & 1.2 \\
\hline 1100 & & & 973.57 & 983.18 & 0.9 \\
\hline 1200 & & & 1071.41 & 1096.7 & 2.3 \\
\hline 1300 & & & 1180.90 & 1195.9 & 1.2 \\
\hline 900 & \multirow{5}{*}{10} & \multirow{5}{*}{10} & 562.96 & 570.86 & 1.4 \\
\hline 1000 & & & 676.68 & 674.62 & 0.3 \\
\hline 1100 & & & 775.76 & 805.67 & 3.7 \\
\hline 1200 & & & 898.21 & 907.07 & 0.9 \\
\hline 1300 & & & 994.69 & 1039.1 & 4.3 \\
\hline 900 & \multirow{5}{*}{15} & \multirow{5}{*}{15} & 353.26 & 319.48 & 10.5 \\
\hline 1000 & & & 428.12 & 404.87 & 5.7 \\
\hline 1100 & & & 510.98 & 484.36 & 5.5 \\
\hline 1200 & & & 632.59 & 574.74 & 10.0 \\
\hline 1300 & & & 753.26 & 730.29 & 3.1 \\
\hline 900 & \multirow{5}{*}{20} & \multirow{5}{*}{20} & 0.00 & 0.00 & 0.0 \\
\hline 1000 & & & 171.30 & 158.53 & 8.0 \\
\hline 1100 & & & 269.13 & 230.69 & 16.6 \\
\hline 1200 & & & 325.40 & 306.32 & 6.2 \\
\hline 1300 & & & 399.27 & 364.92 & 9.4 \\
\hline
\end{tabular}

model and Autodyn-3D hydrocode, respectively. In addition, the proposed model predicts that the residual velocity of the remaining projectile exited from the bielement target is 753 [m/s] whereas, residual velocity of the remaining projectile obtained by the hydrocode is 730 [m/s].

It is seen from the Figs. 7 and 8 that the matching between the analytical and numerical velocity-time histories is good during the ceramic penetration. In addition, a difference between total times of penetration predicted analytically and numerically is exist. This difference increases with impact velocity. This may be attributed to the different in failure models of composites between the analytical and finite difference approaches. This mismatching is clear when penetrating through the composite backup at impact velocity greater than the limit velocity of the target, where the failure of the composite backup occur in few microseconds. Also, we should keep in mind that there was no erosion process defined in composite modelling in order to keep the simplicity of the model. However, the numerical hydrocode evolves more smoothly and naturally due to the erosive process during penetration of the composite material. This conclusion is matching with that obtained by other investigators [1].

Figure 9 plots the analytical and numerical time histories of projectile penetration depth during the penetration of a bi-element target, consisting of $20 \mathrm{~mm}$-thick of $\mathrm{SiC}$ 
ceramic tile backed by $20 \mathrm{~mm}$-thick of Kevlar129 composite plate, at $\mathrm{V}_{\mathrm{i}}=900[\mathrm{~m} / \mathrm{s}]$. Both the analytical model and Autodyn-3D hydrocode predict penetration depths have the similar trends during ceramic tile penetration phases. The difference could be attributed to the difference of the projectile penetration velocity in each approach. A great difference is found during the remaining of projectile penetration into composite plate as mentioned before.

Figure 10 also plots the analytical and numerical predictions of projectile penetration depth-time histories due to the impact of a bi-element target consisting, of $15 \mathrm{~mm}$ thick of $\mathrm{SiC}$ ceramic tile backed by $15 \mathrm{~mm}$-thick of Kevlar129 composite plate, at $\mathrm{V}_{\mathrm{i}}=$ $1300[\mathrm{~m} / \mathrm{s}]$. The matching between the analytical and numerical time-histories of projectile penetration depth is good during the ceramic penetration process. Then, a considerable difference between the two time histories is noticed during the backing composite. This mismatch between the projectile penetration depth-time histories obtained analytically and numerically at the last penetration phase could be attributed to events occurred during the composite penetration by a projectile and may not cover by the analytical model [7].

Figure 11 shows projectile velocity-time history due to the impact of a bi-element target, consisting of $20 \mathrm{~mm}$-thick of $\mathrm{SiC}$ ceramic tile backed by $20 \mathrm{~mm}$-thick of Kevlar129, by a steel projectile with $V_{i}=900$ [m/s]. Figure 12 also shows projectile penetration depth-time history due to the impact of a bi-element target, consisting of $20 \mathrm{~mm}$-thick of SiC ceramic tile backed by $20 \mathrm{~mm}$-thick of Kevlar129, by a steel projectile with $\mathrm{V}_{\mathrm{i}}=900[\mathrm{~m} / \mathrm{s}]$.

\section{CONCLUSIONS}

The main conclusions of the present work are:

- The numerical results obtained by Autodyn-3D for simulating the penetration process of a steel projectile into bi-layered ceramic/composite are in good agreement with their corresponding analytical results of Ref. [7].

- A suitable simulation may be developed to describe the performance of composite materials based on energy absorbed concept as a failure criterion instead of tensile failure criterion.

- The projectile performance during the penetration process may be simulated using Autodyn-3D hydrocode. It may need further investigations to adopt the erosion rate of the projectile. User subroutines could be used to add constitutive equations defining the projectile material behavior.

- Experimental tests are required to determine the parameters included in constitutive equations and failure criteria of the materials fed into numerical simulation codes.

- The obtained numerical results reflect the good predictive capabilities of Autodyn-3D hydrocode in addition to the analytical results. The results must be supported by experimental measurements to check the drawn output from the analytical or numerical technique. 


\section{REFERENCES}

[1] I.S.C. Benloulo and V.S. Galvez, "A New Analytical Model to Simulate Impact onto Ceramic/Composite Armours", Int. J. Impact Engng., Vol. 21, No. 6, pp. 461-471 (1998).

[2] I.S.C. Benloulo, J. Rodriguez and V.S. Galvez, "A Simple Analytical Model to Simulate Textile Fabric Ballistic Impact Behavior", Textile Res. J. (1997).

[3] Z. Fawaz, W. Zheng and K. Behdinan, "Numerical Simulation of Normal and Oblique Ballistic Impact on Ceramic composite Armours", J. Composite Structures, Vol. 63, pp. 387-395 (2004).

[4] M. Mayseless, "Impact on Ceramic Targets", J. Appl. Mech., Vol. 54, pp. 373-378 (1987).

[5] G.J. Peskes and E. Barbero, "Optimization of Lightweight Add-on Armour for Infantry Fighting Vehicles", 17th Int. Symp. on Ballistics, Midrand, South Africa, March 23-27 (1998).

[6] M.M. Shokrieh and G.H. Javadpour, "Penetration Analysis of a Projectile in Ceramic Composite Armour", J. Composite Structures, Vol. 82, pp. 269-276 (2008).

[7] M.A. Shaker and A.M. Riad, Impact of Ceramic/composite Lightweight Targets by High-speed Projectiles ", $13^{\text {th }}$ Int. Conf. on ASAT, Military Technical College, Cairo, Egypt (2009).

[8] R. Cortes, C. Navarro, M.A. Martinez, J. Rodriguez and V.S. Galvez, "Numerical Modeling of Normal Impact on Ceramic Composite Armours", Int. J. Impact Engng., Vol. 12, No. 4, pp. 639-651 (1992).

[9] Century Dynamics, Inc. AUTODYN "Interactive Non-Linear Dynamics Analysis Software", (1997).

[10] "Theory Manual of AUTODYN ", Revision 4.3 (2005).

[11] Y.F. Wang and Z.G Yang, "Finite Element Model of Erosive Wear on Ductile and Brittle Materials", Int. J. Wear, Vol. 265, pp. 871-878 (2008).

[12] D.S. Cronin, K. Bui, C. Kaufmann, G. Mclntosh and T. Brestad, "Implementation and Validation of the Johnson-Homlquist Ceramic Material Model in LS-DYNA", 4 ${ }^{\text {th }}$ European LS-DYNA Users Conference (2003).

[13] R.A. Clegg, D.M. White, W. Riedel and W. Harwick, "Hypervelocity Impact Damage Prediction in Composites: Part I-Material Model and Characterization", Int. J. Impact Engng., Vol. 33, pp. 190-200 (2006). 


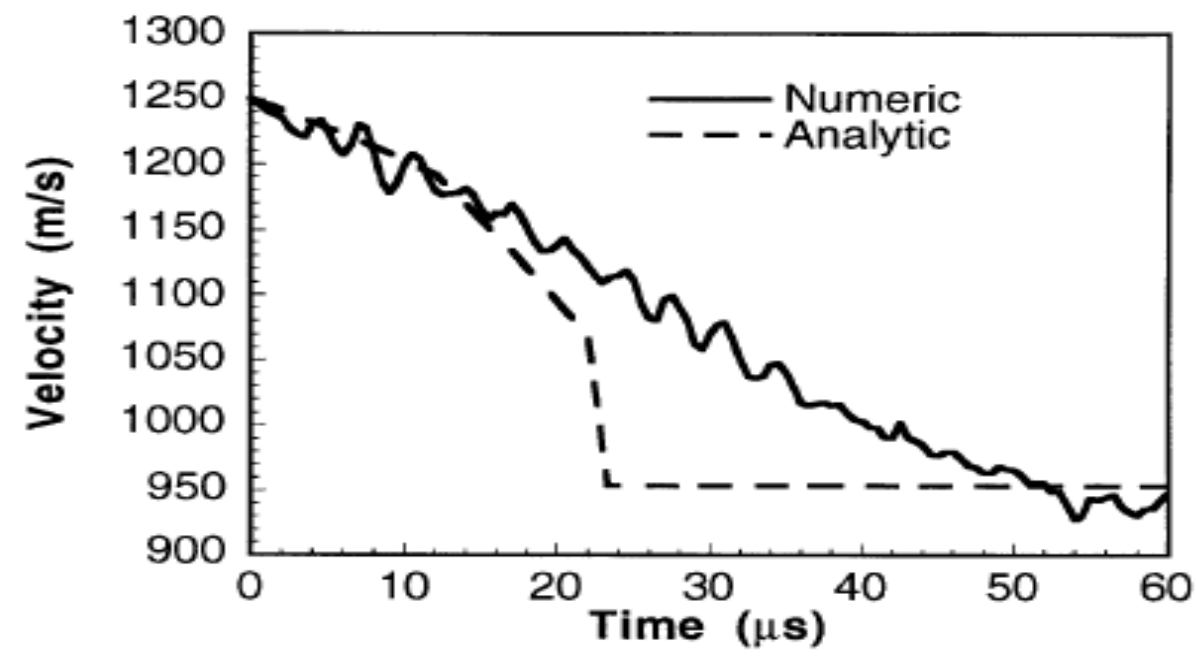

Fig. 1. Different predictions of projectile Velocity-time history [1].

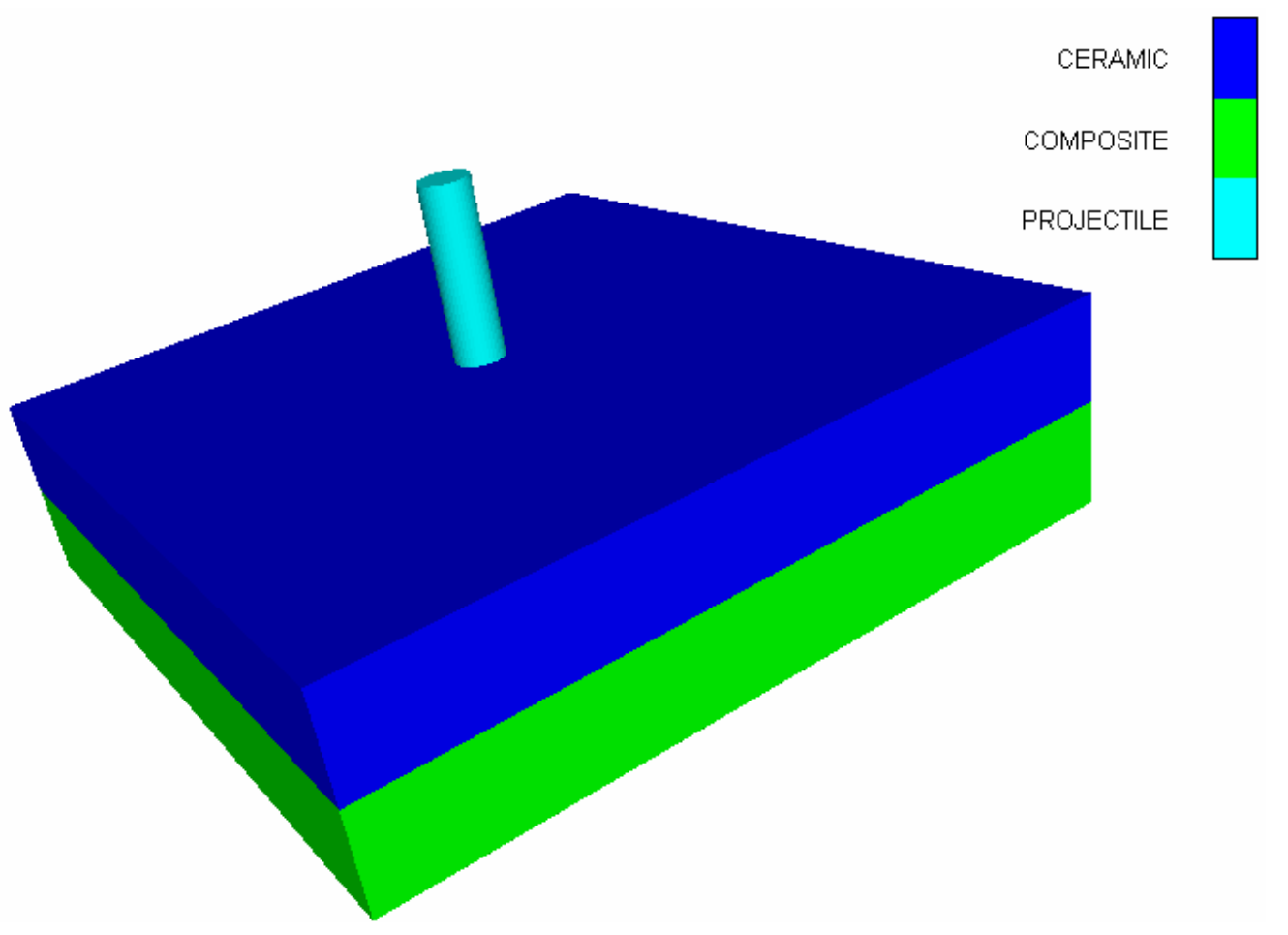

Fig. 2. 3D modelling of projectile, ceramic tile and composite plate in Autodyn-3D hydrocode. 

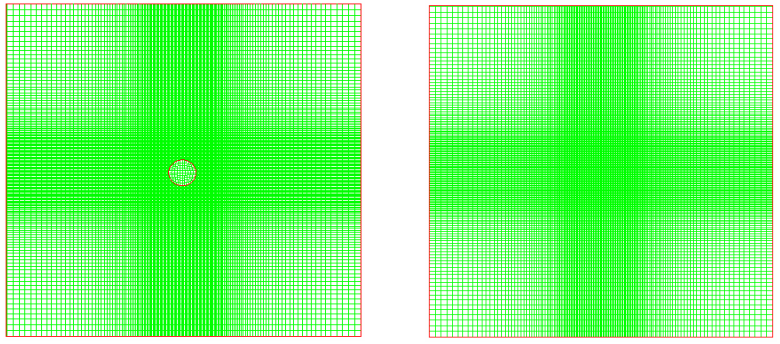

Fig. 3. Front face and back face views of target subgrids.
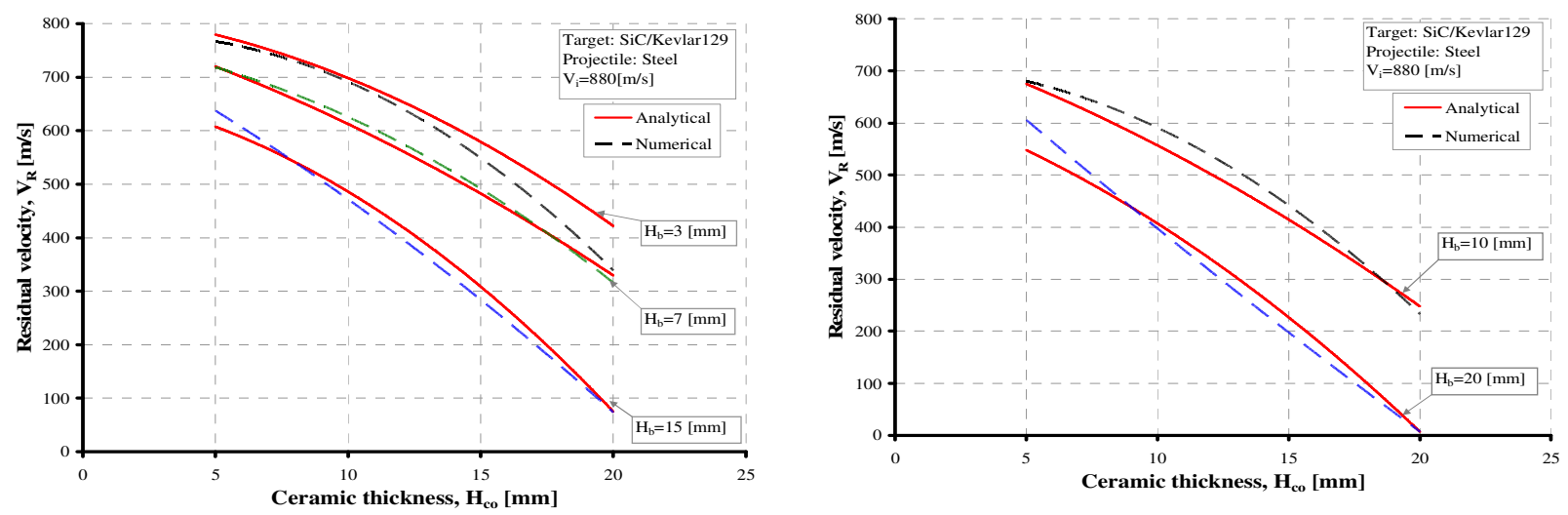

Fig. 5. Comparison between the change of predicted residual velocities with ceramic thickness due to the impact of FSPs into different SiC/Kevlar129 targets with $V_{i}=880[\mathrm{~m} / \mathrm{s}]$ at different composite thicknesses.
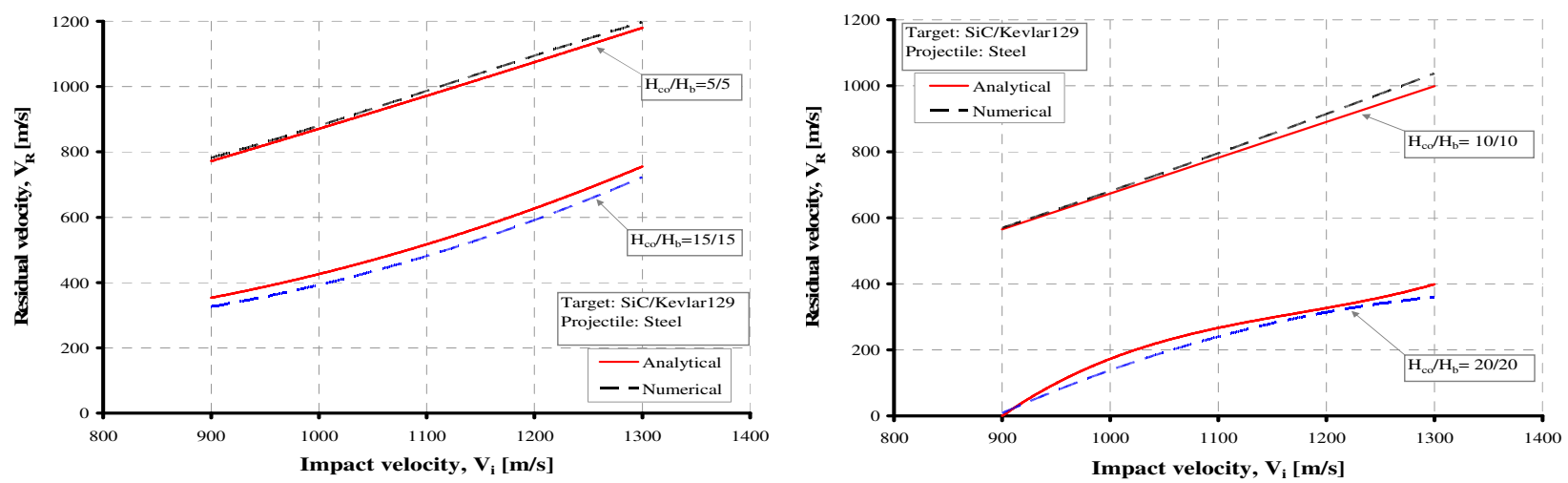

Fig. 6. The change of predicted residual velocities with impact velocity due to the impact of FSPs into different SiC/Kevlar129 targets. 


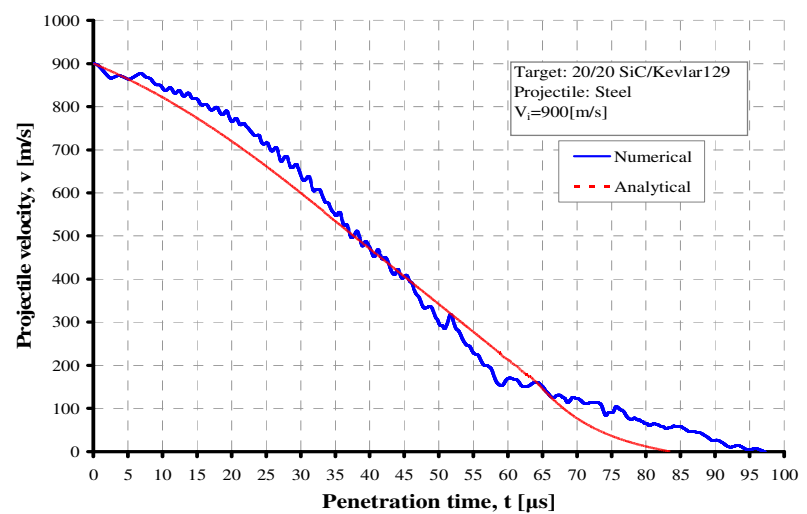

Fig. 7. Predicted velocity-time histories due to the impact of a FSP into 20/20 SiC/Kevlar129 target with $V_{i}=900[\mathrm{~m} / \mathrm{s}]$.

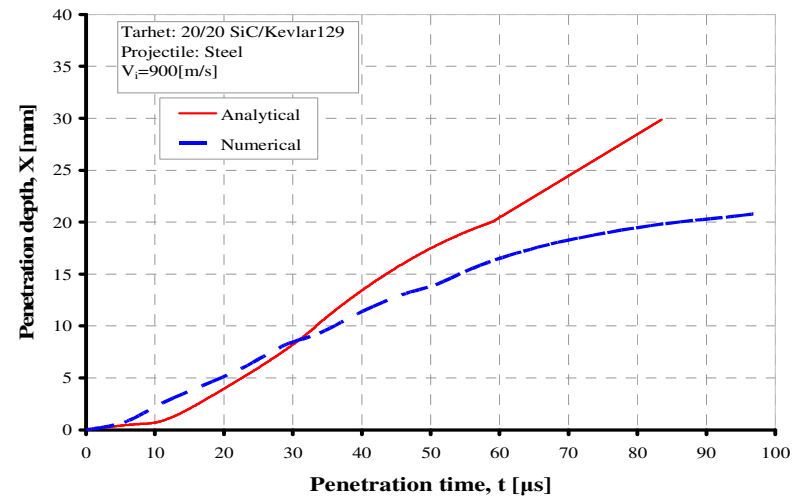

Fig. 9. Predicted projectile penetration depth-time histories due to the impact of a FSP into 20/20 SiC/Kevlar129 target with $\mathrm{V}_{i}=900$ $[\mathrm{m} / \mathrm{s}]$.
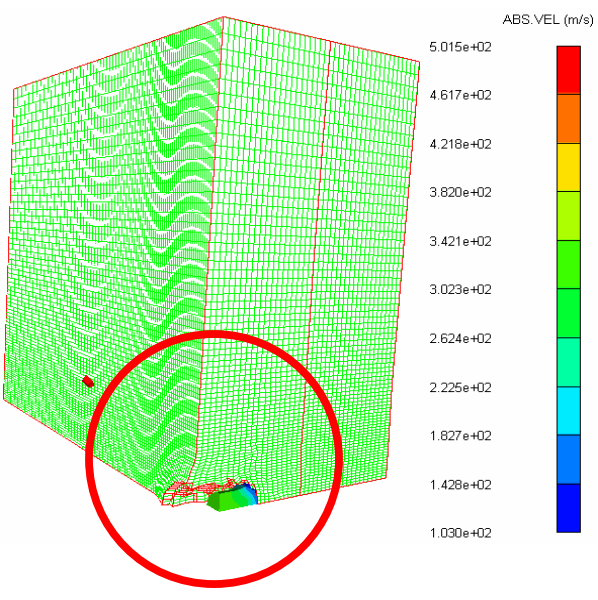

$\mathrm{V}=302[\mathrm{~m} / \mathrm{s}], \mathrm{t}=49.8[\mu \mathrm{s}]$

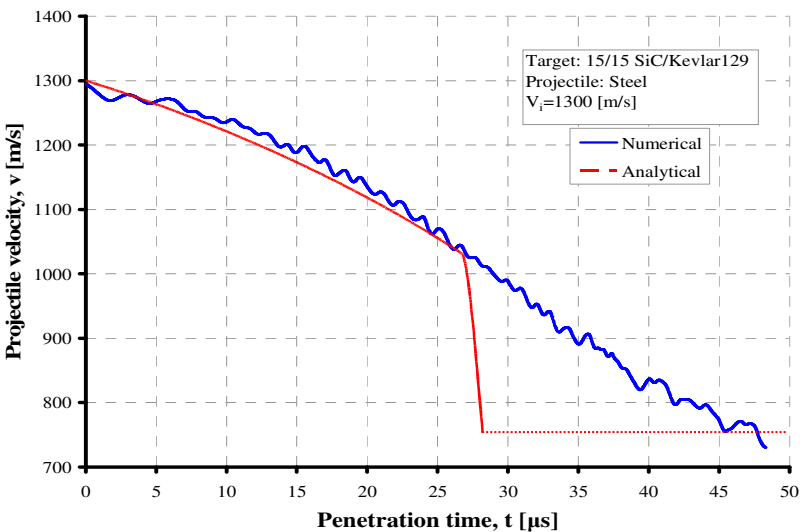

Fig. 8. Predicted velocity-time histories due to the impact of a FSP into 15/15 SiC/Kevlar129 target with $\mathrm{V}_{\mathrm{i}}=1300[\mathrm{~m} / \mathrm{s}]$.

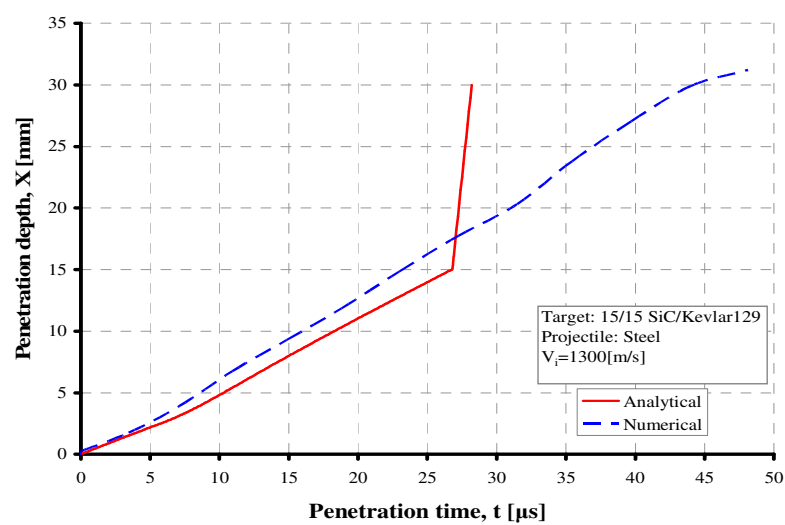

Fig. 10. Predicted projectile penetration depth-time histories due to the impact of a FSP into $15 / 15 \mathrm{SiC} /$ Kevlar129 target with $\mathrm{V}_{i}=1300$ $[\mathrm{m} / \mathrm{s}]$.

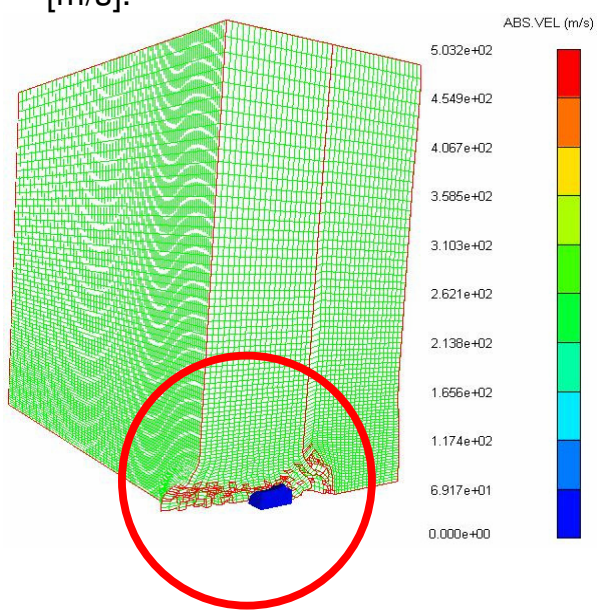

$$
\mathrm{V}=0.0[\mathrm{~m} / \mathrm{s}], \mathrm{t}=97.85[\mu \mathrm{s}]
$$

Fig.11. Projectile velocity-time histories in a bi-element target, consisting of $20 \mathrm{~mm}$-thick of SiC ceramic tile backed by $20 \mathrm{~mm}$-thick of Kevlar-129, due to its impact by a FSP with $V_{i}=900[\mathrm{~m} / \mathrm{s}]$ 


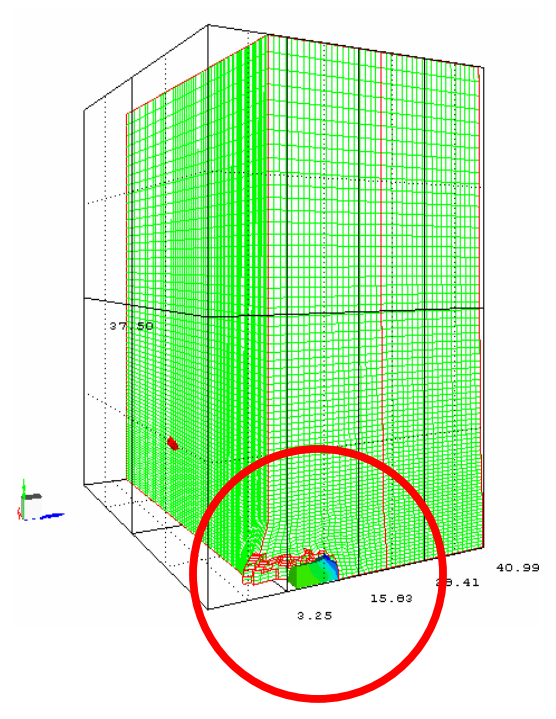

$\mathrm{X}=12.89[\mathrm{~mm}], \mathrm{t}=49.8[\mu \mathrm{s}]$

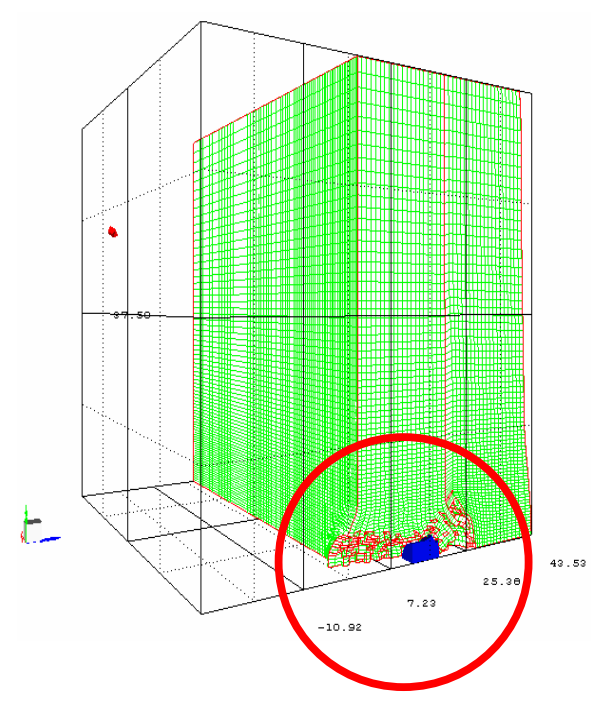

$\mathrm{X}=21.1[\mathrm{~mm}], \mathrm{t}=97.85[\mu \mathrm{s}]$

Fig.12. Projectile penetration depth-time histories in a bi-element target, consisting of $20 \mathrm{~mm}$-thick of SiC ceramic tile backed by $20 \mathrm{~mm}$-thick of Kevlar129, due to its impact by a FSP with $V_{i}=900$ [m/s]. 